\title{
“RECUPERAR O IRRECUPERÁVEL?” - O ADOLESCENTE EM CONFLITO COM A LEI NA MÍDIA: PERCEPÇÕES DE ESTUDANTES DO ENSINO MÉDIO
}

\author{
"RECOVERING THE IRRECUTABLE?" - THE TEEN IN CONFLICT WITH \\ THE LAW IN THE MEDIA: PERCEPTIONS OF MIDDLE SCHOOL STUDENTS
}

\author{
Paulo Roberto Braga Junior* \\ Ernando Brito Gonçalves Junior ${ }^{* \star}$
}

\begin{abstract}
RESUMO
Dentre as diversas mídias capazes de influenciar o debate e a problematização de certos fenômenos sociais, a televisão tem um lugar de destaque. A partir dessa consideração, o objetivo desta pesquisa foi verificar a construção do processo de subjetivação sobre adolescentes em conflito com a lei, tendo como base reportagens de programas televisivos de cunho jornalístico e policial. Buscou-se, também, identificar se as percepções de estudantes do ensino médio de uma escola pública coincidem com os discursos presentes em algumas reportagens televisivas que têm como foco o adolescente autor de ato infracional. Para tanto, utilizou-se, como métodos, a pesquisa bibliográfica, a documental e a pesquisa de campo. Assim, foi possível verificar que determinados programas de televisão operam como violadores de direitos e como reprodutores de estigmas e preconceitos. Quanto aos estudantes que participaram da pesquisa, foi possível identificar nos mesmos um desejo de punições mais severas, além do reconhecimento do impacto causado pelas mídias.
\end{abstract}

Palavras-Chave: Televisão. Sociedade. Reportagens. Impacto.

\begin{abstract}
Among the various media capable of influencing the debate of certain social phenomena, television has a prominent place. Based on this consideration, the objective of this research was to verify the process of subjectivation of adolescents in conflict with the law in reports of televising programs of journalistic and police. It was also sought to identify if the perceptions of high school students of a public school coincide with the speeches present in some television reports about the adolescent author of an infraction. Bibliographic, documentary and field research were used as methods. It has been found that certain television programs constitute violators of rights, reproducers of stigmas and prejudices. As for students, it was possible to identify a desire for more severe punishment and recognition of the impact caused by the media.
\end{abstract}

Keywords: Television. Society. Reportages. Impact.

"Especialista em Mídias na Educação pela Universidade Estadual do Centro-Oeste do Paraná - UNICENTRO e em Educação e Sociedade pelo Instituto Federal do Paraná - IFPR Advogado. Bacharel em Direito pela Universidade Estadual do Norte do Paraná - UENP. Membro do grupo de pesquisa "Ideologias Repressivas do Estado", cadastrado no CNPQ pela UENP. E-mail: pbragajunior@hotmail.com.

" Doutor em História pela Universidade Federal do Paraná - UFPR. Mestre em Educação pela Universidade Federal do Paraná. Professor do departamento de Pedagogia da Universidade Estadual do Centro-Oeste do Paraná- UNICENTRO. E-mail: ernandobrito@gmail.com. 


\section{INTRODUÇÃO}

"Do rio que tudo arrasta se diz que é violento. Mas ninguém diz violentas as margens que o comprimem." Bertolt Brecht

As mídias vêm debatendo, sistematicamente, a temática da violência urbana. Dentre os veículos de comunicação disponíveis no cotidiano da humanidade, a televisão é um dos que mais explora esse tipo de assunto. Além disso, tal veículo abrange, dentre outros assuntos, as condutas e atos, julgados inadequados socialmente, praticados por adolescentes, os quais também integram a violência no meio coletivo.

Propõe-se nesta pesquisa repensar a forma de atuação da mídia televisiva, representada aqui por programas jornalísticos e policiais, na constituição de sentidos sobre o adolescente em conflito com a lei. Como experiência de investigação prática, foram investigadas as percepções de uma turma de estudantes do ensino médio de uma escola pública, localizada em área de vulnerabilidade social, acerca do referido assunto.

A pesquisa trata o problema em questão a partir de três eixos de análise. No primeiro, verifica-se a tendência da abordagem relativa à prática de atos infracionais em alguns programas de TV jornalísticos e policiais. No segundo momento, são demonstradas as questões legais que envolvem os adolescentes e a garantia de sua proteção integral. No terceiro eixo, são verificadas as opiniões de um grupo de estudantes sobre os aspectos que envolvem o adolescente em conflito com a lei e as mídias. Os estudantes que participaram da investigação responderam, após assistirem trechos de programas televisivos, um questionário semiaberto. Para a análise das respostas, os estudantes foram identificados com a letra E, seguida de um número diferenciador.

Para atender aos objetivos destacados, elegeram-se como procedimentos técnicos a pesquisa bibliográfica, documental e de campo. Assim, houve a coleta, a leitura, a análise e a sistematização de estudos e legislações específicas acerca do tema. Foram pesquisadas, também, reportagens sobre adolescentes que cometeram algum ato infracional, disponíveis na internet. Estas serviram para exibição aos alunos, de maneira a verificar suas opiniões sobre o tema. Para a interpretação dos resultados, foi utilizado o método quali-quantitativo.

De modo geral, foi possível verificar que a exploração midiática não promove um amplo debate sobre o tema da delinquência juvenil e, muitas vezes, repercute tão somente em influenciar e reforçar estigmas, bem como viola garantias estabelecidas em lei.

\section{MÍDIAS E CONSTITUIÇÃO DE SENTIDOS SOBRE ADOLESCENTES EM CONFLITO COM A LEI}

As mídias sempre foram importantes instrumentos de constituição de sentidos, pois conseguem influenciar a opinião pública, a partir das formas que apresentam, discutem e debatem determinados assuntos. A televisão, veículo em foco neste trabalho, destaca-se, principalmente, por ter um alcance social abrangente.

Inegavelmente, a influência da televisão é relevante. Kellner (2001) afirma que quando os aparelhos começaram a ser produzidos em massa e ganharam espaço nos lares, um novo modo de se ver e perceber o mundo foi instaurado. O advento da televisão trouxe, certamente, novos paradigmas sociais:

[...] os indivíduos são submetidos a um fluxo sem precedentes de imagens e sons dentro de sua própria casa, e um novo mundo virtual de entretenimento, informação, sexo e política está reordenando percepções de espaço e tempo, anulando distinções entre realidade e imagem, enquanto produz novos modos de experiência e subjetividade (KELLNER, 2001, p.27).

Dessa forma, a televisão, como meio de comunicação abrangente, tem a capacidade de interferir na opinião pública. Para Ferres, "a nossa imagem da realidade é basicamente aquela oferecida pela mídia e principalmente pela televisão. Origina-se aí sua importância social.” (FERRES, 1996, p.59)

Percebe-se, então, que os meios de comunicação, dentre eles a televisão, desempenham um importante papel na constituição da forma como as pessoas entendem e enfrentam certos fenômenos sociais.

Ao discutir certos assuntos, a mídia contribui para moldar o debate de temas políticos e da agenda social. A influência dos meios de comunicação em pautas públicas apoia-se na chamada Teoria do Agendamento (ou agenda-setting), segundo a qual a 
cobertura jornalística afeta tanto "sobre o que" o público pensa, quanto "como" se posiciona acerca de tais assuntos. (ANDI, 2012)

Um exemplo disso pode ser pensado através dos acentuados índices de violência urbana, constantemente veiculado pelas emissoras de TV. Os programas jornalísticos retratam as informações sob determinados enfoques, os quais, em muitos casos, estão ligados a interesses políticos, comerciais e mercadológicos, com preocupação única no lucro e audiência, em detrimento da formação crítica e intelectual do público.

Observa-se que, recorrentemente, as emissoras de televisão brasileiras utilizam-se de programas do gênero informativo policial para atrair audiência. (ROMÃO, 2013). As formas de abordagens que esses programas utilizam, geralmente com tom sensacionalista, refletem na forma em que a sociedade passa a discutir temas de ordem pública, como o combate à criminalidade, a modificação de leis e a punição de infratores.

Dessa forma, o noticiário policial não apenas veicula informações, mas também produz modos de compreender a realidade, à medida que constrói imagens ou identidades por meio daquilo que é apresentado ao público.

[...] além de produzir certos modos de existência e de vida, de estar nas mãos de uns poucos, a mídia funciona organizando diversos e diferentes fluxos de acontecimentos; pela via do espetáculo, das formas dramáticas e sensacionalistas produz identidades, simpatias, prós e contras. (COIMBRA, 2004, p. 03)

Tais aspectos ficam muito visíveis quando os programas televisivos policiais tratam de questões referentes aos adolescentes em conflito com a lei. A forma que as reportagens são apresentadas pode influenciar no processo de subjetivação desses sujeitos, reforçando a construção de estigmas e preconceitos.

É possível identificar nesses programas de TV fragrante desrespeito à legislação e aos direitos humanos de adolescentes que, supostamente, cometeram atos infracionais.

Em apenas 30 dias, narrativas de rádio e TV promoveram 4.500 violações de direitos, cometeram 15.761 infrações a leis brasileiras e multilaterais e desrespeitaram 1.962 vezes normas autorregulatórias. Esses são alguns dos principais resultados da análise de 28 programas "policialescos" produzi- dos em 10 capitais do País, realizada pela ANDI — Comunicação e Direitos. (VARJÃO, 2016, p.6)

A maioria dos programas de TV brasileiros, de natureza policial, transmite conteúdos de maneira sensacionalista, a qual é caracterizada por posturas incisivas e performáticas de apresentadores e repórteres, além do uso exagerado de certas expressões e imagens, que têm a finalidade de causar impactos e chocar a opinião pública. No discurso, tais programas se referem aos adolescentes utilizando expressões pejorativas, tais como "marginal", "menino bandido", "garoto boca quente" e "criatura", as quais podem despertar emoções nos telespectadores, diante das mais variadas mazelas sociais. (FIGUEIRÓ; MINCHONI; FIGUEIRÓ, 2013).

O uso desses termos favorece o discurso de que o "marginal" não é merecedor da piedade social, anula o valor humano do adolescente, além de insinuar que nem o Estado e nem a sociedade têm responsabilidades sobre esse sujeito. (MACHADO; PESSETTI, 2016)

As notícias são acompanhadas de comentários discriminatórios, os quais são feitos pelos apresentadores e direcionados aos adolescentes. Em algumas reportagens, os adolescentes são pressionados com perguntas constrangedoras feitas pelos repórteres e têm suas imagens expostas, fatos que violam disposições legais.

Esses programas de TV esquecem que, para além do ato infracional, existe ali um adolescente, o qual, em muitos casos, cresceu com a falta de acesso aos direitos sociais mínimos para a existência humana, previstos na Constituição Federal. Não se considera que estes sujeitos estão em peculiar condição de desenvolvimento (cognitivo e emocional) e que as influências externas são muito relevantes na construção de suas subjetividades.

A mídia televisiva sensacionalista contribui para o processo de estigmatização social de adolescentes pobres e envolvidos em atos infracionais. Ao transmitir notícias colocando-os em situações vexatórias, expondo suas imagens de forma indevida e tecendo comentários que violam direitos, pode-se incentivar no público espectador o desejo de uma punição fora dos parâmetros legais.

Quase nunca se vê nessa mídia a tentativa de discutir e compreender a realidade de vida desses 
adolescentes, bem como os motivos que os levaram a cometer determinadas infrações ou irregularidades. O adolescente é rotulado de forma desconectada de sua história de vida.

Em geral, a discussão costuma se dar sob o enfoque policialesco, e o assunto é abordado numa perspectiva individual, deixando em segundo plano uma reflexão mais ampla sobre a problemática: direitos humanos e políticas sociais são, na maioria das vezes, aspectos raramente associados a essa pauta. (ANDI, 2012, P.13)

Essa mídia reivindica cada vez mais castigos a esses adolescentes. Pouco se fala sobre a necessidade de prevenção da criminalidade, da garantia de direitos e diminuição da desigualdade social, sobre políticas públicas de promoção da juventude, sobre programas de ressocialização e reinserção social. De modo geral, raramente as reportagens, principalmente as de programas sensacionalistas, são acompanhadas de discussões de caráter mais amplo e crítico.

Esse tipo de abordagem, rasa e carregada de preconceitos, pode levar o telespectador a concluir que a redução da maioridade penal é a solução para o problema da violência. Cria-se o desejo de punição, severa e até desproporcional, dessa parcela da população, sem qualquer preocupação com seu tratamento.

Esse desejo de punição, que extrapola os limites impostos pela a lei, é acompanhado, geralmente, por falas que expressam que a luta pelos direitos humanos é o mesmo que defender bandidos, reforçando o discurso daqueles que pressionam para a diminuição da maioridade penal.

Outra situação que pode ser observada, diante das reportagens coletadas para a análise, é como as abordagens são distintas conforme a classe social do adolescente. Quando o ato infracional é cometido por um adolescente de classe média alta, o comum é que a denominação "adolescente" prevaleça e que a abordagem tenha foco no questionamento das circunstâncias que o levaram a cometer o ato. No entanto, se o adolescente é pobre e da periferia, esses questionamentos não são feitos.

Segundo a Agência de Notícias dos Direitos da Infância - ANDI, entre as consequências do modelo "policialesco", estão as distorções na percepção do fenômeno dos adolescentes em conflito com a lei, com impactos negativos no modo de enfrentá-lo:
Não se deve também negligenciar os efeitos da superexposição desses indivíduos sobre a opinião pública - o que, neste caso, acaba provocando distorções consideráveis no modo de compreensão e enfrentamento do grave fenômeno dos adolescentes em conflito com a lei. (VARJÃO, 2016, p.55)

Tal visão produz sentidos que estigmatizam e marginalizam ainda mais os referidos adolescentes, que, por condições sócio-históricas, já carregam a exclusão no seu percurso de vida. Segundo as professoras MACHADO e PESSETTI (2016, p. 1352):

Os efeitos de sentidos observados rememoram dizeres já-ditos que valorizam/defendem/legitimam a punição pelo viés do castigo desumanizado, bem como, promove o esquecimento da legislação que norteia as políticas para os adolescentes em conflito com a lei.

É importante ressaltar que não é intenção da presente pesquisa defender que a condição de vida dos adolescentes que cometem atos infracionais é um elemento capaz de afastar a responsabilização por tais atos. No entanto, a aplicação das sanções deve considerar aspectos dessa peculiar condição de desenvolvimento e que o tratamento deve ser de acordo com o que está estabelecido na legislação vigente.

Sendo assim, a mídia televisiva sensacionalista cria pré-conceitos e pode interferir na opinião pública ao tratar de questões referentes aos adolescentes em conflito com a lei, que, muitas vezes, tiveram suas vidas marcadas pela negação e violação de direitos. Isto resulta num processo de subjetivação que dificulta processos de habilitação social e transformação na histórias desses sujeitos marginalizados.

\section{A CONCEPÇÃO DO ADOLESCENTE COMO SUJEITO DE DIREITOS}

A construção da noção de "adolescência" dentro da sociedade e a forma de enfrentamento daqueles envolvidos em atos infracionais passaram por um processo histórico, de modo a transformar-se ao longo do tempo. E isso pode ser aferido pelo conjunto de leis que buscam orientar o tratamento dispensado aos adolescentes.

Em 1990, no contexto de muitos movimentos e de grupos que questionavam o tratamento dado às crianças e adolescentes no Brasil, e já na vigência da 
nova Constituição Federal de 1988, foi promulgado o Estatuto da Criança e do Adolescente (ECA) - Lei $8.069 / 90$. É por meio desta lei que se que sustenta todo o aspecto jurídico do adolescente, inclusive no cometimento de ato infracional.

A Constituição Federal de 1988, em seu artigo 227, consagrou em nosso ordenamento a doutrina da proteção integral, estabelecendo deveres à família, à sociedade e ao Estado quanto à garantia de direitos para crianças e adolescentes. (BRASIL, 1988). Assim, a promoção do desenvolvimento humano e da cidadania das crianças e adolescentes tem base numa tríplice responsabilidade compartilhada.

A família, a sociedade e o poder público tornam-se corresponsáveis nas ações de efetivação de direitos. Segundo o art. 18 do ECA, todos devem zelar pela dignidade da criança e do adolescente, pondo-os a salvo de qualquer tratamento desumano, violento, aterrorizante, vexatório ou constrangedor. (BRASIL, 1990).

O artigo 15 do ECA afirma que: "A criança e o adolescente têm direito à liberdade, ao respeito e à dignidade como pessoas humanas, em processo de desenvolvimento e como sujeitos de direitos civis, humanos e sociais garantidos na Constituição e nas leis". (BRASIL, 1990). A nova concepção baseia-se no entendimento de que crianças e adolescentes são sujeito de direitos.

O ECA veio estabelecer novas formas de enunciar a infância e a adolescência, assegurando-lhes o gozo de todos os direitos fundamentais, inerentes à pessoa humana. Desta forma:

A adoção da compreensão presente no ECA, em substituição ao velho modelo da situação irregular, acarretou mudanças de referências e práticas, com reflexos inclusive no trato da questão infracional. No plano legal, essa substituição representou uma opção pela inclusão social do adolescente em conflito com a lei, tratado ao longo da história como mero objeto de intervenção. (PARANÁ, 2005, p.4)

A criança passa a ser definida de maneira mais específica com o ECA, que a considera como a pessoa com até doze anos de idade incompletos e adolescentes aqueles entre doze e dezoito anos de idade.

A doutrina da proteção integral a crianças e adolescentes, reconhecida pelo ECA, instituiu atendimentos e garantias especiais, pelo fato destes se constituírem como sujeitos em processo de desenvolvimento e titulares de direitos fundamentais.

Nesse contexto, verifica-se que somente em 1988 a criança passa a ser tratada juridicamente enquanto prioridade da política pública. Entretanto, é somente em 1990, com o ECA, que se institui no direito brasileiro a expressão 'a criança e o adolescente' enquanto sujeito de direitos. Esse marco rompe, juridicamente, com a concepção do "menor" para inaugurar o tempo da promoção e proteção integral e absoluta da infância. (ANJOS; REBOUÇAS, 2014, p. 10)

O termo "menor" passa a ser considerado inadequado, pois possui significado pejorativo, sendo socialmente relacionado à criança e ao adolescente delinquente ou marginal. A denominação "em conflito com a lei" passa a ser utilizada, pois estabelece uma condição temporal e superável. $\mathrm{O}$ adolescente não "é", ele "está" em conflito com a lei. As expressões "delinquente", "bandido" e "marginal" desenvolvem estigmas, que podem ser de difícil superação. (LASKOSKI; OLIVEIRA, 2016)

Outro ponto importante estabelecido pelo ECA, por meio do seu artigo 103, foi a definição do ato infracional, o qual é tido como a conduta descrita como crime ou contravenção penal pratica por crianças ou adolescentes.

O ECA considera que são inimputáveis as crianças e adolescentes até os 18 anos. No entanto, o adolescente em conflito com a lei deverá responder a um procedimento para apuração do ato infracional e, se comprovada a autoria e materialidade do ato, será aplicada uma medida socioeducativa, prevista no artigo 112 do Estatuto. Há o entendimento de que o adolescente possui necessidades peculiares que não são contempladas, por exemplo, pelo Código Penal, aplicado aos adultos.

É relevante observar-se que as medidas socioeducativas também contêm o aspecto sancionatório, como resposta à sociedade pela infração cometida, mas seu propósito final é a reintegração social por meio de aspectos educativos. Nesse sentido, as medidas devem ter cunho predominantemente pedagógico e a medida de internação constitui-se na medida mais severa e excepcional.

A medida socioeducativa de privação de liberdade, que consiste em período de internação em centro socioeducativo, pode ser aplicada a partir dos 12 anos 
de idade. O período máximo de internação, determinado pela lei, são de três anos. Tal medida deverá ser cumprida em entidade exclusiva para adolescentes. Durante o período de internação, inclusive provisória, serão obrigatórias atividades pedagógicas e garantido o direito à escolarização. (BRASIL, 2009)

Todas as medidas devem atender a objetivos educativos, ou como enunciado, socioeducativos, preservando e garantindo direitos fundamentais, tais como a convivência familiar, a escolarização obrigatória, entre outros, e, em se tratando da medida de internação, brevidade e excepcionalidade. (COSSETIN, 2012)

Diante do exposto, verifica-se que a consideração pela infância e adolescência deve enunciar-se sob novos aspectos. $\mathrm{O}$ atendimento destinado a esses sujeitos de direitos deve ser considerado uma política pública com fundamento em direitos subjetivos, garantidos pela doutrina da proteção integral.

\section{REFLEXÕES EM SALA DE AULA SOBRE O ADOLESCENTE EM CONFLITO COM A LEI NAS MÍDIAS}

A seguir serão apresentados os resultados obtidos através da pesquisa sobre a exposição midiática do adolescente em conflito com a lei, na perspectiva dos estudantes do ensino médio de uma escola pública.

Para a realização dessa intervenção prática, foi escolhido um colégio estadual localizado num bairro periférico da cidade de Jacarezinho/PR, cujos alunos são de classes sociais menos favorecidas. A coleta de dados deu-se de forma coletiva. Para isso, foram utilizadas duas aulas, de 50 minutos cada, da disciplina de Sociologia.

Houve o consentimento prévio da direção escolar, do professor responsável pela turma e dos alunos. Contou-se com a participação de 21 estudantes do $3^{\circ}$ ano do ensino médio. A idade dos alunos participantes varia bastante, entre 16 a 21 anos, o que evidencia a distorção idade-série presente na turma. As respostas das questões abertas passaram pela técnica de análise de conteúdo, sendo os textos divididos em unidades e categorias semelhantes. (BARDIN, 2004)

A atividade iniciou-se com breves reflexões sobre quais as mídias os alunos conhecem e o quanto estas fazem parte do seu cotidiano. Em seguida, os alunos foram direcionados, através do debate estabelecido, para discussões sobre a mídia televisiva. Os alunos responderam oralmente quais os temas mais presentes nos programas jornalísticos. Dentre as respostas, obteve-se o tema violência.

Nesse momento, houve a oportunidade de refletir que muitos casos de violência mostrados na TV, envolvem adolescentes como autores de atos inflacionais. Sem muitos comentários, para que não houvesse influência nas respostas, foi entregue um questionário composto por uma questão objetiva e outra discursiva. Primeiramente, os estudantes assinalaram a quantidade de horas diárias que costumam assistir televisão. Predominaram as opções: menos de 1 hora (11 alunos) e entre 1 e 2 horas ( 6 alunos). As respostas denotam que tais estudantes não dedicam um tempo considerável do dia à televisão. Evidentemente, essa mídia pode estar sendo substituída por outros recursos como celulares e outros eletrônicos com internet.

O segundo questionamento dessa fase da pesquisa buscou revelar quais os significados que envolvem o adolescente em conflito com a lei, na perspectiva dos estudantes. A pergunta discursiva "O que você pensa do adolescente que comete atos inflacionais? Qual sua motivação e punição necessária?" trouxe respostas que, após analisadas, fizeram emergir opiniões semelhantes, as quais se repetiram no discurso de vários estudantes. Desse modo, foram estabelecidas como categorias e verificada a quantidade de alunos que as expressavam.

As categorias mais citadas foram: houve falha na família (13 estudantes); esses adolescentes precisam de ajuda e oportunidades (11 estudantes); esses adolescentes querem/optaram por uma vida fácil (09 estudantes) e a importância da educação escolar ou a falta dela como motivo (7 estudantes).

Nessas respostas vemos a predominância de discursos de culpabilização das famílias e daqueles que indicam a vontade própria dos adolescentes como determinantes para a delinquência. No entanto, quando reconhecem que os mesmos precisam de ajuda e oportunidades, levam em conta o contexto social que os envolvem. Ao darem ênfase à negligência familiar, os estudantes mostraram que ainda não reconhecem a responsabilidade compartilhada entre esta, a sociedade e o Estado. Obviamente, o núcleo familiar é um importante fator para a formação e para a educação de crianças e adolescentes, porém, não se pode reduzir a problemática da violência juvenil a ações do 
próprio sujeito ou de sua família. Segundo o Programa Nacional de Direitos Humanos - $3^{\text {a }}$ versão:

Marcadas pelas diferenças e por sua fragilidade temporal, as crianças, os adolescentes e os jovens estão sujeitos a discriminações e violências. As ações programáticas promovem a garantia de espaços e investimentos que assegurem proteção contra qualquer forma de violência e discriminação, bem como a promoção da articulação entre família, sociedade e Estado para fortalecer a rede social de proteção que garante a efetividade de seus direitos. (BRASIL, 2010, p.53)

Dentre aqueles que responderam sobre a punição necessária, predominaram as categorias: desejo de pena de prisão (08 estudantes), sentimento de impunidade (07 estudantes).

Quanto ao aspecto punitivo, as perspectivas no sentido de prisão dos adolescentes infratores podem revelar os anseios pela redução da maioridade penal, vista, muitas vezes, como o principal método para se evitar a impunidade. Sendo esta uma pauta constante nos veículos de comunicação de massa como a única alternativa para a solução para o fenômeno da violência praticada por adolescentes.

Segundo Varjão (2016), em levantamento da ANDI - Agência de Notícias dos Direitos da Infância, observou-se que no noticiário policial predominam os percentuais de narrativas que pregam punições mais severas aos adolescentes, propostas de mudança na legislação e redução da maioridade penal. Como defendido no decorrer deste trabalho, dificilmente se consegue avançar para um debate mais amplo sobre as soluções para as violências/criminalidade.

Soluções mais abrangentes e vinculadas à dimensão preventiva, como investimento em educação, criação de espaços públicos de lazer e esporte, investimento em políticas de combate às desigualdades socioeconômicas e étnico-raciais, ou investimento em ações educativas voltadas para o respeito à diversidade ficaram em patamares inferiores a $0,5 \%$ cada. Somadas, elas correspondem exatamente a exíguos 0,5\% do total. (VARJÃO, 2016, p.106)

Finalizada essa parte da atividade, seguiu-se para a exibição de três vídeos, que consistiam em reportagens de canais da televisão aberta, envolvendo adolescentes em conflito com a lei.

A primeira reportagem mostrou um adolescente que, após o cometimento de atos inflacionais, foi encontrado nu, ferido e amarrado a um poste num bairro carioca. A reportagem mencionou que o grupo responsável pela ação é conhecido como "justiceiros". Ao final, a apresentadora, depois de comentar que o que resta ao "cidadão de bem" é se defender, diz: "E aos defensores dos direitos humanos, que se apiedaram do marginalzinho preso ao poste, eu lanço uma campanha. Faça um favor ao Brasil: adote um bandido!"”.

O segundo vídeo mostrou a resposta de um apresentador ao questionamento "Como se corrige um menor infrator?". Ele expressou enfaticamente que há menores infratores que são incorrigíveis e que não há como se recuperar o irrecuperável. O apresentador fez críticas à "pedagogia do amor" e disse que, durante o período de internamento, os "vagabundos de menor idade" deveriam "comer capim". O mesmo apresentador levantou questões relacionadas à impunidade que envolve estes adolescentes e sugere a necessidade da mudança nas leis.

A terceira reportagem mostrou quatro adolescentes num local que, supostamente, seria uma delegacia, os quais foram apreendidos, acusados pela prática de ato infracional. $\mathrm{O}$ apresentador narrou que os referidos jovens, por não permanecerem detidos, se tornaram "veteranos no crime". Na reportagem não houve preocupação em preservar a imagem dos adolescentes, visto que, em alguns momentos, foi possível visualizar seus rostos, e foi dada evidência às tatuagens presentes em seus corpos. O repórter que estava no local dirige o microfone a um dos adolescentes que se encontrava de cabeça baixa e perguntou: "você falou que é bandido?". Diante da negativa do adolescente em responder, o repórter insistiu: "tem que falar agora, no microfone! Longe não adianta nada!”. O adolescente permaneceu de cabeça baixa, sem fazer a afirmação de que era bandido, como o repórter desejava. Na sequência da reportagem, os adolescentes em todos os momentos eram referidos como "bandidos".

Com os exemplos desses programas de TV, propostos aos alunos, demonstra-se que com a intenção de denunciar a violência cometida por adolescentes, essas produções televisivas adotaram, do mesmo modo, um discurso extremamente violento e que pode ser influenciador. As suas formas de dizer e mostrar os atos cometidos revelaram uma hierarquia agressiva, na qual os jornalistas, representando as pessoas de 
bem, revelam desprezo pelos sujeitos adolescentes, ditos criminosos e bandidos.

Após a exibição, seguida desses três vídeos, sem estimular comentários, foi entregue aos estudantes um segundo questionário, composto por duas questões abertas.

A primeira pergunta tinha como enunciado: "Diante das reportagens apresentadas, você concorda como o meio de comunicação apresentou a notícia e os adolescentes envolvidos?". Ao analisar as respostas, identificou-se que, dos 21 estudantes, apenas 3 reprovaram a forma com que o meio de comunicação transmitiu a notícia e o tratamento dado aos adolescentes. Justificaram suas respostas da seguinte forma:

Não, pois o Estado e sociedade também têm culpa, se o governo tivesse dado suporte e oportunidades, conscientizando e melhorando a educação, não teria motivos para cometer tal infração. (E 1)

Com esse argumento acima, tem-se a única menção entre os alunos à ineficácia da proteção estatal e da sociedade como fator que propicia o ingresso do adolescente na criminalidade. Este Estado tem o dever de promover a defesa dos direitos de crianças e de adolescentes preconizados pela Constituição Federal e de maneira mais direta no ECA, dever que também é da sociedade, da qual a mídia notadamente faz parte.

Os outros 2 alunos, que discordaram da abordagem televisiva, expressaram-se nos seguintes termos:

Não foi adequada a forma que foi apresentada a notícia, pois por estar em uma emissora transmitida para milhões de pessoas foi antiético. (E 2)

Não foi adequada, é antiético, mas se não fosse falado dessa maneira não teria tanta repercussão a notícia. (E 3)

É importante a menção acima sobre a questão ética, haja visto que o direito à liberdade de expressão não pode se sobrepor ao direito que qualquer cidadão tem de não ser humilhado e condenado na televisão, ainda que suspeito de ter cometido um crime. O artigo $6^{\circ}$ do Código de Ética dos Jornalistas Brasileiros diz que: "é dever do jornalista: opor-se ao arbítrio, ao autoritarismo e à opressão, bem como defender os princípios expressos na Declaração Universal dos Direitos Humanos". (FENAJ, 2007)

Para os demais estudantes, as formas discriminatórias e contrárias à lei no tratamento dispensado aos adolescentes nos programas de TV não repercutiram negativamente, pois a maioria dos estudantes, além de serem favoráveis aos atos expostos pela mídia, repetiu falas/opiniões que foram expressas nas reportagens, como a impunidade e necessidade de mudança nas leis:

Sim, pois estes jovens envolvidos não são nenhuma vítima, então merecem toda repugnância [...] bandido bom é bandido morto. (E 4)

Concordo plenamente com os apresentadores que apresentaram os telejornais. (E 5)

Tem que tomar decisões abusivas [em relação aos adolescentes] senão ficará assim ou pior. (E 06)

Foi muito adequada a forma como foi dita. (E 07)

Sim, pois foi como um alerta para a sociedade. (E 08)

Sim, pois esses adolescentes devem ser punidos, presos, como o de maior. (E 09)

Sim, porque os apresentadores expressaram os sentimentos que eles tinham a revolta, porque eles eram menores de idade e tinham várias passagens pela polícia e isso para eles eram nada, porque eles sabiam que iam ser soltos novamente por causa de ser menor de idade. (Aluno 10)

Como base nas respostas acima, é possível observar que a maioria dos estudantes não só concordou com o tratamento dado aos adolescentes, e com a forma de exposição destes na mídia, como também estruturou suas respostas de forma semelhante ao discurso dos jornalistas. Revelou-se nas respostas o desejo de punição sem problematizar as origens das violências e sem considerar a fase peculiar de desenvolvimento desses sujeitos.

O jornalismo policial, ao apelar para as imagens do ocorrido, parece se valer da dificuldade do indivíduo pseudoformado em contextualizar e dar sentidos para sua experiência imediata: aquilo que a câmera conseguiu capturar é tomado como a verdade completa, e nenhuma reflexão faz-se necessária. (ROMÃO, 2013, p.147)

Para Araújo (2016) a mídia apresenta, frequentemente, a inimputabilidade das pessoas menores de 18 anos de idade como causa do aumento das ocorrências nessa área. Tal abordagem leva a população a exigir a redução da idade penal e se solidarizar apenas com as vítimas dos adolescentes. Além disso, os adolescentes que cometeram ato infracional são, de modo geral, nomeados de maneira inadequada de menores, bandidos e marginais. Estimula-se, 
também, reclamações quanto à garantia dos direitos humanos dos adolescentes. Do mesmo modo, a mídia e os membros da coletividade se valem de discursos como: "onde estão os direitos humanos das vítimas?", ou ainda, "direitos humanos devem ser para humanos direitos!". Assim, abafa-se um olhar crítico e social sobre esses adolescentes que, muitas vezes, vivem em estado de vulnerabilidade social.

O segundo e último questionamento, feito após a exibição dos vídeos foi: "Na sua opinião a mídia produz algum tipo de impacto na compreensão do tema pelo telespectador?". Apenas um aluno afirmou não haver o referido impacto, enquanto os demais acreditam haver impacto na compreensão do adolescente infrator, de acordo com sua exposição midiática:

Sim, pois é um dos meios de comunicação mais utilizados pela população podendo influenciar milhares de pessoas [...] essas reportagens tentam impor um pensamento e fazer com que a população ache que esse é o certo. (E 11)

O telespectador é influenciado pela mídia [...] pela mídia acabam mudando sua maneira de pensar e agir sobre eles [adolescentes em conflito com a lei]. (E 12)

Causam impacto na opinião das pessoas sim, porque o apresentador passa ao telespectador a realidade sobre o menor infrator, eles roubam, matam, traficam e nada acontece. (E 13)

Ao abordar a temática que envolve a mídia televisiva, compreende-se que as pessoas assistem a esse veículo de diferentes maneiras. No entanto, Kellner (2001) indica que é possível reconhecer que há um movimento de homogeneização revelado na reprodução de seus discursos. Para Bordieu (1997) há um poder simbólico na comunicação via TV, sendo preciso entender quais os possíveis movimentos desenvolvidos por quem o recebe.

Conclui-se que, ao analisar todos os dados coletados, que a maioria dos estudantes manifestou o entendimento de que o adolescente em conflito com a lei passou por dificuldades em seu desenvolvimento (familiares, falta de oportunidades, falta de educação escolar) e que estas colaboraram para suas atitudes. No entanto, mesmo diante destas constatações, de que as condições de vida contribuíram para suas condutas, não houve a indicação significativa da necessidade de alternativas e políticas para que os adolescentes superem tais condições sociais que lhes foram impostas.
Pode-se constatar que o desejo de punição mais severa (redução da maioridade penal revelada no desejo da pena de prisão) é muito presente entre os participantes da pesquisa, discurso que já era expresso em suas respostas mesmo antes da exibição das reportagens.

Quanto a abordagem midiática e seus impactos, a grande maioria dos estudantes aprovou o discurso presente nas reportagens e, praticamente todos estudantes, reconheceram que a exposição do tema gera efeitos na opinião dos telespectadores.

Sem dúvidas, a forma depreciativa de exposição dos adolescentes nesses noticiários favorece o fortalecimento de discursos de estigmatização e criminalização.

\section{CONSIDERAÇÕES FINAIS}

Como foi demonstrado, a mídia televisiva tem um alcance social abrangente, e, como consequência, aquilo que ela veicula costuma ganhar credibilidade junto à população. Para muitos, as informações e conteúdos transmitidos recebem um caráter de verdades absolutas e inquestionáveis. Por esta razão, além de repassar informações, é notória a capacidade da TV de formar e influenciar a opinião de seus espectadores.

No entanto, em muitos casos, a sociedade recepta mensagens que são veiculadas pela mídia sem, necessariamente, refletir sobre as mesmas e suas possíveis realidades.

Em relação à abordagem do adolescente em conflito na lei, realizada por alguns noticiários de cunho policial e jornalístico, difunde-se uma percepção negativa e estereotipada de um sujeito que, na maior parte dos casos, vive uma realidade dotada de diversos tipos de violência, como a familiar, as Estatais e as sociais.

Portanto, é desconsiderado que o sujeito é fruto de uma construção sócio-histórica, e que, por trás desse adolescente rotulado de "bandido", há tantas negligências de direitos, que, apesar de garantidos, não lhe foram ofertados.

A exposição midiática analisada faz parecer que o cometimento de atos infracionais retira do adolescente a garantia de sua dignidade, porém, segundo a legislação, pressupõe-se medidas aplicadas com finalidades pedagógicas e sancionatórias. A menção à importância de se investir em prevenção de violências 
em nenhum momento foi observada nas reportagens analisadas.

O fenômeno da adolescência envolvida em atos infracionais é um problema social complexo, cuja resolução não cabe à redução da maioridade penal, tão defendida nos programas de TV que foram tomados como exemplo nesta pesquisa. Exige-se, necessariamente, um trabalho intersetorial entre os órgãos pertencentes à rede de proteção à criança e ao adolescente (educação, saúde, segurança, assistência social, entre outros), e uma articulação efetiva de todas esferas governamentais (União, estados, municípios), com o intuito de interromper a continuidade do ciclo de violências, discriminação e contradições sociais.

Entende-se que o adolescente pobre, denominado "bandido", pode tomar este estigma como aquilo que a sociedade espera dele, de modo a abraçar a condição que lhe foi imposta, dificultando o estabelecimento de um novo projeto de vida dentro das normas sociais preestabelecidas.

Nas entrevistas feitas com os estudantes, foi possível perceber que a maioria deles associa os adolescentes que estão em conflito com a lei com as desigualdades sociais, as quais, evidentemente, são fatores de risco para suas condutas. No entanto, quando os estudantes participantes da pesquisa responderam sobre a punição, demonstraram a defesa pela aplicação da penalidade mais severa aos jovens infratores, a pena de prisão.

Os estudantes não reconheceram nas reportagens exibidas a violação de direitos humanos fundamentais de crianças e adolescentes. Em suas respostas concordaram com a exposição midiática realizada com total descaso quanto à proteção da dignidade.

Percebemos que a maioria dos estudantes, mesmo nas respostas antes de assistirem as reportagens, já tinham um discurso semelhante aos adotados pelos meios de comunicação, e, após assistirem os vídeos, reproduziram falas e ideias expressas pelos apresentadores de TV.

Conclui-se assim que, além do provável impacto da mídia na constituição de sentidos sobre o adolescente em conflito com a lei, há a necessidade premente de se falar de direitos humanos e de dignidade humana nas escolas, como forma de aprofundar debates e trazer contribuições para as problemáticas sociais.

\section{REFERÊNCIAS}

ANDI - Agência de Notícias dos Direitos da Infância. Direitos em Pauta: Imprensa, Agenda Social e Adolescentes em Conflito com a Lei. Brasília: ANDI, 2012.

ANJOS, L.; REBOUÇAS, G. M. Da Concepção Do "Menor" Ao Surgimento Da Criança E Do Adolescente Enquanto Sujeitos De Direitos: Uma Compreensão Histórica. In: XXIII Congresso Nacional do CONPEDI, 23. João Pessoa, 2014. Anais... João Pessoa: CONPEDI, 2014. p. 192-211. Disponível em: <http://publicadireito.com.br/ artigos/?cod=fec16d1d594dae3d $>$. Acesso em 04 mar.2018.

ARAÚJO, D. B. de. Adolescentes em conflito ou não com a lei: mídia, representação social e direitos humanos. Tese (Doutorado em Psicologia) - Faculdade de Filosofia e Ciências Humanas, Universidade Federal da Bahia. Salvador, 2016. Disponível em: https://repositorio.ufba.br/ ri/handle/ri/20951. Acesso em 12 jul.2018.

BARDIN, L. Análise de conteúdo. Lisboa: Edições 70, 2004.

BOURDIEU, P. O poder simbólico. Tradução Fernando Tomaz. Lisboa: Difel, 1989.

BRASIL. Constituição (1998). Constituição da República Federativa do Brasil: promulgada em 5 de outubro de 1988. Disponível em: http://www.planalto.gov.br/ccivil_03/ constituicao/constituicaocompilado.htm. Acesso em 10 fev.2018.

. Lei ${ }^{0} 8.069$ de 13 de julho de 1990. Estatuto da Criança e do Adolescente. Disponível em: http://www. planalto.gov.br/ccivil_03/Leis/L8069.htm. Acesso em 10 fev.2018.

Programa Nacional de Direitos Humanos (PNDH3). Secretaria de Direitos Humanos da Presidência da República. Brasília: SDH/PR, 2010.

COIMBRA, C. M. B. Mídia e produção de modos de existência. In: Psicologia: Teoria e Pesquisa, 17 (1), p. 1-4, 2004, p.3. Disponível em <http://www.scielo.br/pdf/ptp/ v17n1/5399.pdf>. Acesso em 28 fev. 2018.

COSSETIN, M. Socieducação no Estado do Paraná: os sentidos de um enunciado necessário. 2012. 190f. Dissertação (Mestrado em Educação) - Universidade Estadual do Oeste do Paraná. Cascavel - PR, 2012. Disponível em:http://200.201.88.199/portalpos/media/File/ educacao/Dissertacao_marcia_cossetin.pdf . Acesso em 16 fev.2018.

FENAJ - FEDERAÇÃO NACIONAL DOS JORNALISTAS. Código de Ética dos Jornalistas Brasileiros. 2007. Disponível em: http://www.fenaj.org.br/federacao/ cometica/codigo_de_etica_dos_jornalistas_brasileiros.pdf. Acesso em: 23 ago. 2018.

FERRÉS, Joan. Televisão e Educação. 1. Ed. Porto Alegre: Artes Medicas, 1996. 
FIGUEIRÓ, R. de A.; MINCHONI, T.; FIGUEIRÓ, M. E. S. da S. A Produção do Adolescente "Infrator" na Mídia Brasileira. In: Congresso Internacional de Direito e Contemporaneidade. 2., 2013, Santa Maria, Anais..., Santa Maria, 2013, p. 222 - 234. Disponível em: http://coral.ufsm. br/congressodireito/anais/2013/2-5.pdf. Acesso em 28 fev. 2018.

KELLNER, Douglas. A Cultura da Mídia. São Paulo: Edusc, 2001.

LASKOSKI, L.M.; OLIVEIRA, M. Histórico da Legislação sobre o atendimento do Adolescente em Conflito com a Lei. Formação em Ação SEED-PR, Curitiba - PR, p. 01-10, fev. 2016. Disponível em: www.educadores.diaadia.pr.gov.br/ arquivos/File/formacao.../deja_fa_roteiro.pdf Acesso em: 23 mar.2018

MACHADO, R. V.; PASSETTI, M. C. C. "Faça um favor ao Brasil: adote um bandido"- a constituição dos sentidos sobre o sujeito adolescente em conflito com a lei no telejornal "SBT Brasil". Fórum Linguístico, Florianópolis, v 13, n. 3, p. 1351 -1362, 2016. Disponível em: https://periodicos.ufsc.br/ index.php/forum/article/view/19848412.2016v13n3p1351. Acesso em 12 mar. 2018.

PARANÁ. Secretaria de Estado da Educação. Superintendência da Educação. Programa de Educação nas Unidades Socioeducativas. Curitiba: SEED, 2005. Disponível em: http://www.gestaoescolar.diaadia.pr.gov. br/arquivos/File/sem_pedagogica/fev_2014/proeduse.pdf. Acesso em 18 fev. 2018.

ROMÃO, D. M. M. Jornalismo Policial: Indústria Cultural e Violência. 2013, 206 f. Dissertação (Mestrado em Psicologia) - Instituto de Psicologia da Universidade de São Paulo, São Paulo, 2013. Disponível em: www.teses. usp.br/teses/disponiveis/47/47131/tde-30072013.../romao_ corrigida.pdf Acesso em 15 mar. 2018

VARJÃO, S. Violações de direitos na mídia brasileira: Pesquisa detecta quantidade significativa de violações de direitos e infrações a leis no campo da comunicação de massa. Brasília, DF: ANDI, 2016. 